\title{
Catalyst and Process Design for the Continuous Manufacture of Rare Sugar Alcohols by Epimerization- Hydrogenation of Aldoses
}

\author{
Giacomo M. Lari, ${ }^{[a]}$ Olivier G. Gröninger, ${ }^{[a]}$ Qiang Li, ${ }^{[b]}$ Cecilia Mondelli, ${ }^{*[a]}$ Núria López, ${ }^{*[b]}$ and \\ Javier Pérez-Ramírez ${ }^{*[a]}$
}

\begin{abstract}
Sugar alcohols are applied in the food, pharmaceutical, polymer, and fuel industries and are commonly obtained by reduction of the corresponding saccharides. In view of the rarity of some sugar substrates, epimerization of a readily available monosaccharide has been proposed as a solution, but an efficient catalytic system has not yet been identified. Herein, a molybdenum heteropolyacid-based catalyst is developed to transform glucose, arabinose, and xylose into less-abundant mannose, ribose, and lyxose, respectively. Adsorption of molybdic acid onto activated carbon followed by ion exchange to the cesium form limits leaching of the active phase, which greatly improves the catalyst stability over $24 \mathrm{~h}$ on stream. The hydrogenation of mixtures of epimers is studied over ruthenium cat-
\end{abstract}

alysts, and it is found that the precursor to the desired polyol is advantageously converted with faster kinetics. This is explained by density functional theory on the basis of its more favorable adsorption on the metal surface and the lower energy barrier for the addition of a hydrogen atom to the primary carbon atom. Finally, different designs for a continuous process for the conversion of glucose into mannitol are studied, and it is uncovered that two reactors in series with one containing the epimerization catalyst and the other containing a mixture of the epimerization and hydrogenation catalysts increases the mannitol/sorbitol ratio to 1.5 from 1 for a single mixed-bed reactor. This opens a prospective route to the efficient valorization of renewables to added-value chemicals.

\section{Introduction}

Sugar alcohols, particularly those with $C_{5}$ and $C_{6}$ backbones, are an important class of carbohydrate derivatives. Pentose-derived polyols include arabitol, xylitol, and ribitol, whereas mannitol and sorbitol are the most relevant representatives of hexose-derived alcohols, which comprise a higher number of molecules owing to the presence of an additional stereocenter. All these molecules have multiple uses in the fine chemical, pharmaceutical, and food industries. ${ }^{[1]}$ Specifically, they improve the nutritional profile of food preparations, as they are often incompletely absorbed by the intestine, ${ }^{[2]}$ marginally alter blood sugar levels, ${ }^{[3]}$ and appear to limit the formation of body fat. ${ }^{[4]}$ They are also added to toothpaste and chewing gum formulations for their anticaries effect, as oral bacteria cannot ferment them. ${ }^{[5]}$ Additionally, they are relevant and ver-

[a] G. M. Lari, O. G. Gröninger, Dr. C. Mondelli, Prof. J. Pérez-Ramírez Institute for Chemical and Bioengineering

Department of Chemistry and Applied Biosciences ETH Zurich

Vladimir-Prelog-Weg 1, 8093 Zurich (Switzerland)

E-mail: cecilia.mondelli@chem.ethz.ch jpr@chem.ethz.ch

[b] Q. Li, Prof. N. López

Institute of Chemical Research of Catalonia, ICIQ

The Barcelona Institute of Science and Technology

Av. Països Catalans 16, 43007 Tarragona (Spain)

E-mail:nlopez@iciq.es

$\square$ Supporting Information and the ORCID identification number(s) for the
(D) author(s) of this article can be found under http://dx.doi.org/10.1002/ cssc. 201600755. satile monomers for the manufacture of highly performing biodegradable and biocompatible materials ${ }^{[6]}$ and renewable feedstocks for the preparation of chemicals ${ }^{[7]}$ and fuels. ${ }^{[8]}$ Notably, arabitol has recently entered the list of the top-12 biobased

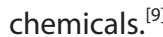

Sugar alcohols are rarely isolated from natural products and are more commonly obtained by hydrogenation of the corresponding carbohydrates. This has mostly been achieved by means of enzymes, ${ }^{[10]}$ although chemocatalytic technologies have also been proposed. ${ }^{[11]}$ The latter systems feature a lower environmental and economic impact owing to the possibility of processing reactants at higher concentrations and of operating over wider $\mathrm{pH}$ and temperature ranges. ${ }^{[12]}$ Aldoses are the substrates of choice, ${ }^{[13]}$ as the formation of a hydroxyl group from a primary carbonyl function does not generate a stereocenter and the reaction can proceed with high selectivity. Nevertheless, the very low availability of certain sugars (e.g., mannose and ribose) limits the feasibility of obtaining some of the polyols at a large scale. ${ }^{[14]}$ Two approaches have been proposed to overcome this problem. The first comprises the use of a suitable ketose, as in the case of fructose for the preparation of mannitol. ${ }^{[15]}$ Here, the drawback is the formation of approximately equimolar mixtures of mannitol and sorbitol, which have to be separated by costly crystallization or chromatography techniques. ${ }^{[16]}$ Indeed, attempts to increase the selectivity to mannitol by modification of the catalyst ${ }^{[17]}$ or by the addition of a chiral organic co-catalyst ${ }^{[18]}$ have only led to moderate success. Alternatively, the abundant epimeric form of 
a rare sugar could be chosen as the starting material, and the desired polyol could be obtained by combining epimerization and hydrogenation steps. ${ }^{[19]}$ Remarkably, this strategy could be applied to sugars such as pentoses, for which the ketonic form is infrequent. Raney nickel and $\mathrm{Ru} / \mathrm{C}$ have been shown to be effective hydrogenation catalysts, ${ }^{[11]}$ whereas the best heterogeneous epimerization materials reported so far have shown limitations with respect to the concentration of the substrate owing to the requirement of using methanol as the medium $(S n-\beta)^{[20]}$ or to their level of activity (layered niobium molybdate). ${ }^{[21]}$ Besides, only few catalytic data are available for solids prepared by immobilizing the highly active but water-soluble ${ }^{[22]}$ phosphomolybdic heteropolyacid (HPA) through adsorption onto activated charcoal ${ }^{[23]}$ or by precipitation in the form of an insoluble salt. ${ }^{[24]}$ Most relevant$l y$, the combination of the two reactions has never been studied in detail, and the application of industrially more amenable reactors in flow mode instead of vessels in batch mode has not been explored.

Herein, we target the preparation of rare sugar alcohols by epimerization followed by hydrogenation. In particular, we focus on the synthesis of mannitol

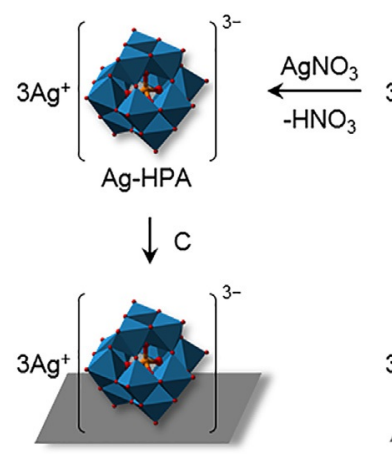

Ag-HPAC

\section{Results and Discussion}

\section{Design of the epimerization catalyst}

Bulk and supported molybdenum-based catalysts were prepared to evaluate their activity and stability in sugar epimerization (Scheme 1). The first group included phosphomolybdic from glucose, ribitol from arabinose, and arabitol from xylose. We initially confront various methods for the immobilization of HPA by evaluating the epimerization activity of the silica-supported, carbon-supported, and ion-exchangeresin-supported materials obtained and by investigating their compositional and structural changes upon use in continuousflow catalytic runs. After selecting an efficient and stable hydrogenation catalyst based on ruthenium, we investigate the relative hydrogenation rates of the starting sugars and their epimers by combining kinetic tests and density functional theory (DFT) simulations. Finally, we study the overall performance of a continuous process by comparing different arrangements of the catalysts in single and series reactor configurations. acid in its protonic form and as its silver and cesium salts. ${ }^{[2]}$ The second set was obtained by adsorption of the acid or the salt on silica, activated carbon, ${ }^{[23]}$ or an ion-exchange resin (IER). ${ }^{[25]}$ Compositional data (Table 1) confirmed the expected molybdenum contents in the bulk solids. In the case of the supported catalysts, high metal loadings were observed that corresponded to up to $75 \%$ uptake of the precursor applied in the preparation. The Mo/P ratio was used to estimate the preservation of the heteropolyacid nature (Scheme 1) of the active phase upon synthesis. The typical value of phosphomolybdic acid (12) was obtained in most cases. A notable exception was the material prepared by using the IER, which lost part of the phosphoric acid groups. This was ascribed to the limited stability of the heteropolyacid at $\mathrm{pH}>3$, which resulted in depletion of its Keggin-type structure and the formation of molybdate and phosphate ions. ${ }^{[26]}$ Finally, the $M o / M$ ratio $(M=A g, C s)$ was considered to evaluate the efficiency of the proton exchange.

\begin{tabular}{|c|c|c|c|c|c|c|c|c|}
\hline Catalyst & $\begin{array}{l}\mathrm{Mo}^{[\mathrm{b}]} \\
{[\mathrm{wt} \%]}\end{array}$ & $\mathrm{Mo} / \mathrm{P}^{[c]}$ & $\mathrm{Mo} / \mathrm{M}^{[\mathrm{c}]}$ & $\begin{array}{l}S_{\mathrm{BET}}^{[\mathrm{d}]} \\
{\left[\mathrm{m}^{2} \mathrm{~g}^{-1}\right]}\end{array}$ & $\begin{array}{l}V_{\text {pore }}^{[\mathrm{e}]} \\
{\left[\mathrm{mL} \mathrm{g}^{-1}\right]}\end{array}$ & $\begin{array}{l}\operatorname{TOF}^{[f]} \\
{\left[\mathrm{h}^{-1}\right]}\end{array}$ & $\begin{array}{l}S_{M}{ }^{[g]} \\
{[\%]}\end{array}$ & $\begin{array}{l}\text { Mo leaching }{ }^{[\mathrm{b}]} \\
{[\%]}\end{array}$ \\
\hline $\mathrm{MoO}_{3}$ & 73.5 & - & - & 15 & 0.21 & 1.8 & 95.7 & 100 \\
\hline H-HPA & 65.6 & 12.8 & - & 7 & 0.06 & 28.9 & 93.6 & 100 \\
\hline $\mathrm{Ag}-\mathrm{HPA}$ & 48.1 & 10.9 & 3.5 & 41 & 0.18 & 31.1 & 89.9 & 21 \\
\hline Cs-HPA & 49.7 & 11.5 & 3.8 & 61 & 0.16 & 29.1 & 89.4 & 13 \\
\hline H-HPA/IER & 12.2 & 15.9 & - & 21 & 0.07 & 15.4 & 91.5 & 3 \\
\hline $\mathrm{H}-\mathrm{HPA} / \mathrm{SiO}_{2}$ & 18.6 & 11.8 & - & 105 & 0.35 & 35.4 & 95.1 & 61 \\
\hline $\mathrm{H}-\mathrm{HPA} / \mathrm{C}$ & 25.5 & 12.4 & - & 581 & 0.41 & 51.8 & 93.4 & 16 \\
\hline $\mathrm{Ag}-\mathrm{HPA} / \mathrm{C}$ & 20.1 & 12.6 & 5.2 & 629 & 0.45 & 60.7 & 92.8 & 4 \\
\hline Cs-HPA/C & 16.1 & 13.1 & 5.5 & 654 & 0.42 & 55.4 & 90.2 & 2 \\
\hline
\end{tabular}

[a] Reaction conditions: $T=333 \mathrm{~K}$, [glucose] $=0.28 \mathrm{M}$, glucose $/ \mathrm{Mo}=50, t=30 \mathrm{~min}$. [b] ICP-OES. [c] XRF. [d] BET method. [e] Volume of $\mathrm{N}_{2}$ adsorbed at $p / p_{0}=$ 0.99. [f] Based on Mo. [g] Selectivity to mannose. 
This was close to the theoretical value of 4 for the bulk AgHPA and Cs-HPA, whereas it was significantly higher for the carbon-supported materials, indicating that part of the exchanged metal was lost (Table 1). This can be explained by the ionic nature of the interaction between the support and the active phase, as hinted by previous reports describing that positively charged sites on the carbon surface act as cations displacing the $\mathrm{Ag}^{+}$and $\mathrm{Cs}^{+}$species. ${ }^{[23]}$ The porous properties of the catalysts were determined by nitrogen sorption. The data evidence that H-HPA possessed an even lower specific surface area $\left(S_{\mathrm{BET}}\right)$ than the reference material $\mathrm{MoO}_{3}$, whereas the $S_{B E T}$ values of Ag-HPA and Cs-HPA were markedly higher. ${ }^{[27]}$ Carbon-supported catalysts displayed high porosity $\left(V_{\text {pore }}\right)$ and total surface areas $\left(S_{B E T}\right)$ greater than $500 \mathrm{~m}^{2} \mathrm{~g}^{-1}$. Nevertheless, it should be noted that these values are substantially lower than those of the bare carbon $\left(V_{\text {pore }}=0.61 \mathrm{mLg}^{-1}\right.$ and $S_{\mathrm{BET}}=1100 \mathrm{~m}^{2} \mathrm{~g}^{-1}$ ). This points to significant pore blockage upon deposition of large quantities of the heteropolyacid. The same was observed in the case of the silica-supported material. Incorporation of the active phase reduced the $S_{B E T}$ of the bare support by $20 \mathrm{~m}^{2} \mathrm{~g}^{-1}$ and its $V_{\text {pore }}$ by $0.15 \mathrm{~mL} \mathrm{~g}^{-1}$. In the case of the IER-supported solid, no differences were observed relative to the pristine carrier. $\mathrm{H}_{-}, \mathrm{Ag}_{-}$, and $\mathrm{Cs}-\mathrm{HPA}$ deposited on carbon were amorphous, as no distinctive reflections were observed by X-ray diffraction (Figure S1 a in the Supporting Information). On the other hand, $\mathrm{H}-\mathrm{HPA} / \mathrm{SiO}_{2}$ and the bulk materials showed typical reflections of the Keggin-type phosphomolybdic acid. The very sharp diffraction lines point to crystals $>100 \mathrm{~nm}$ in size Taking into account the substantially different loadings of the elements, energy-dispersive X-ray spectroscopy (EDS) mapping of the Cs-HPA/C catalyst (Figure $1 \mathrm{a}$ ) displayed homogeneous distributions of $\mathrm{Cs}, \mathrm{Mo}$, and $\mathrm{P}$ on the carbon support, in line with a high dispersion of the active phase. Additionally, the absence of areas enriched in Mo or $\mathrm{P}$ pointed to a preserved heteropolyacid structure.

The catalytic activities of the prepared materials were tested in the batch epimerization of glucose to mannose. The heteropolyacid-based catalysts exhibited better performances than the bulk molybdenum oxide (Table 1 and Table S1), as expected on the basis of previous evidence. ${ }^{[22]}$ Interestingly, the exchange of protons by cesium or silver cations did not influence the reaction rate significantly, in line with the fact that protons do not partake in the reaction, ${ }^{[28]}$ but the material became less soluble and only $13-21 \%$ of the molybdenum leached from the solids into the reaction mixture.

The immobilization of molybdic acid onto solid supports led to inferior (IER carrier), similar $\left(\mathrm{SiO}_{2}\right.$ carrier), or doubled (C carrier) activity. The enhancement in the turnover frequency (TOF) in the latter case (Table 1) is possibly due to a better dispersion of the active phase. The amount of Mo leached varied over a very broad range. Specifically, the maximum (61\%) was observed in the case of the silica-supported solid and the minimum (3\%) for H-HPA/IER. This indicates that ionic interactions, which were expected to be the only means for immobilization onto the IER, are most beneficial to anchor the active phase in a stable manner, whereas weak dipolar interactions, such as those acting in the case of silica, are ineffective. Both mecha-
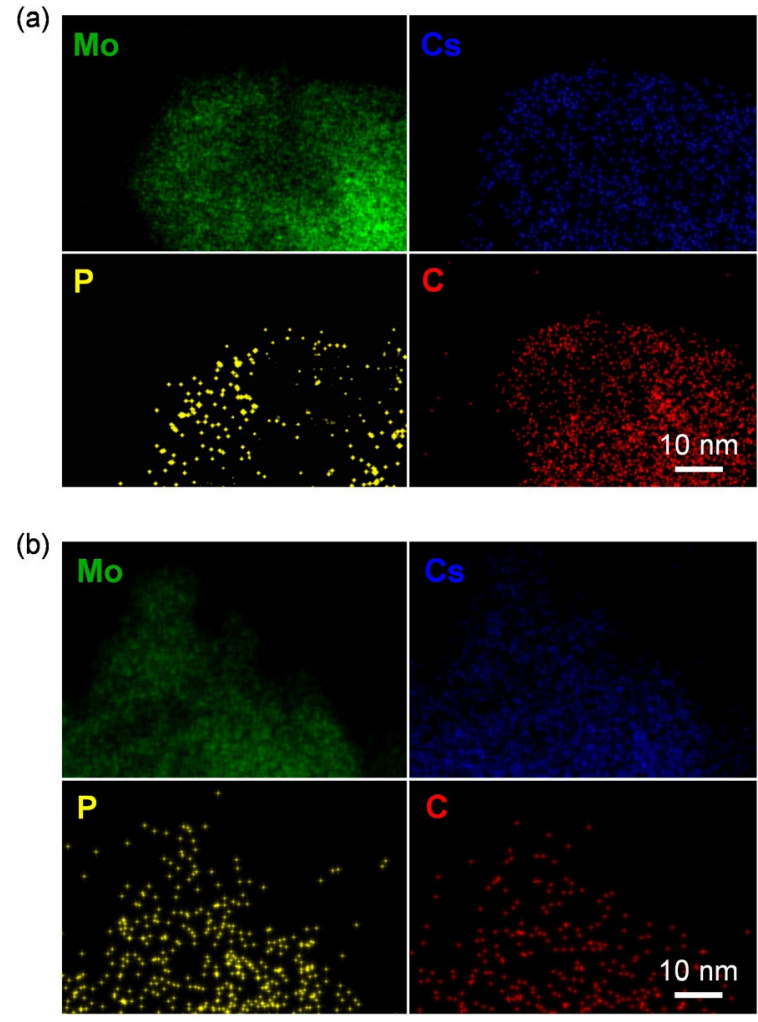

Figure 1. EDS mapping of Mo, Cs, P, and C for Cs-HPA/C in (a) fresh and (b) used forms.

nisms likely play a role in the deposition of HPA on carbon, ${ }^{[23]}$ which rationalizes the intermediate leaching observed by using this carrier. Immobilization of the ion-exchanged HPAs produced catalysts showing activities and selectivities comparable to those shown by $\mathrm{H}-\mathrm{HPA} / \mathrm{C}$, in line with the testing of the bulk materials featuring different counterions. Still, these solids were more stable, as metal depletion was similar to that of the robust H-HPA/IER. Also in this case, the presence of a different counterion did not significantly alter the activity or selectivity. On the basis of its high activity and robustness, Cs$\mathrm{HPA} / \mathrm{C}$ was chosen to investigate the temperature dependence of the reaction and the catalyst stability upon repeated use. Regarding the first aspect, a negligible glucose conversion was observed below $313 \mathrm{~K}$, whereas it steadily increased between 333 and $373 \mathrm{~K}$ (Figure $2 \mathrm{a}$ ). The Mo leaching over 10 cycles was higher than $80 \%$ in the case of $\mathrm{H}-\mathrm{HPA} / \mathrm{C}$ but was limited to only $35 \%$ in the case of Cs-HPA/C (Figure 2 b). Notably, in both cases, the Mo/P ratio did not change, which likely indicates that the Keggin-type structure was maintained. On the basis of these results, Cs-HPA/C was tested in continuous mode under industrially relevant, that is, high-conversion, conditions (Figure $2 \mathrm{c}$ ). A minor activity loss was observed over the first $12 \mathrm{~h}$ on stream, whereas deactivation became more pronounced in the subsequent $12 \mathrm{~h}$ of the test. The major reason for the activity loss seems to be the substantial (45\%) depletion of the Mo content, as determined by elemental analysis. It should be noted that, despite significant deactivation, the stability of this optimized catalyst was found to be greatly superior to that of 

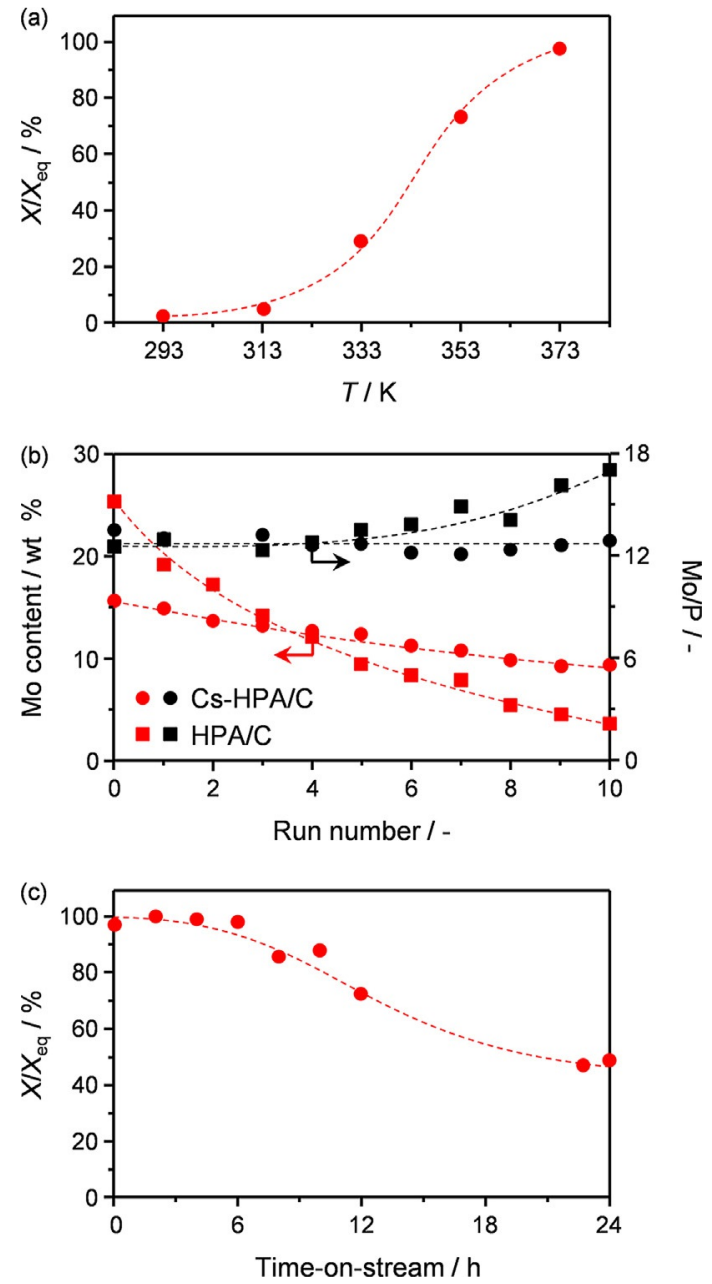

Figure 2. (a) Glucose conversion (relative to the equilibrium) as a function of temperature over Cs-HPA/C. (b) Variation in the molybdenum content and the molar molybdenum-to-phosphorous ratio upon consecutive batch runs over H-HPA/C and Cs-HPA/C at $333 \mathrm{~K}$. (c) Glucose conversion (relative to the equilibrium) versus time-on-stream during continuous experiments over Cs$\mathrm{HPA} / \mathrm{C}$ at $363 \mathrm{~K}$.

previously reported materials. The used catalyst was analyzed by transmission electron microscopy (TEM)-EDS (Figure $1 \mathrm{~b}$ ), which showed that the fine distribution of the active phase was preserved. The slightly decreased intensity of the $\mathrm{Cs}, \mathrm{Mo}$, and $P$ signals in the map of the used sample is in line with leaching (Table 1). Finally, Cs-HPA/C was evaluated in the epimerization of arabinose to ribose and of xylose to lyxose. In both cases, high selectivities were attained (Table 2), and the turnover frequencies were similar to that obtained in the conversion of glucose, which confirmed the versatility of this catalyst with respect to the nature of the saccharide substrate.

\section{Design of the hydrogenation catalysts}

For the hydrogenation of glucose/mannose, xylose/lyxose, and arabinose/ribose mixtures obtained by epimerization of the first more naturally abundant sugar over molybdate-based materials, the catalyst selection relied on literature studies on the reduction of fructose to mannose. Ruthenium supported on

\begin{tabular}{|llll|}
\hline $\begin{array}{l}\text { Table 2. Performance of } \mathrm{Cs}-\mathrm{HPA} / \mathrm{C} \text { in the epimerization of arabinose and } \\
\text { xylose. }\end{array}$ & \\
Reaction & $\begin{array}{l}X_{\mathrm{eq}}^{[\mathrm{b}]} \\
{[\%]}\end{array}$ & $\begin{array}{l}\mathrm{TOF}^{[\mathrm{c}]} \\
{\left[\mathrm{h}^{-1}\right]}\end{array}$ & $\begin{array}{l}\mathrm{S}_{\text {epimer }}{ }^{[\mathrm{d}]} \\
{[\%]}\end{array}$ \\
\hline $\begin{array}{l}\text { arabinose } \leftrightarrow \text { ribose } \\
\text { xylose } \leftrightarrow \text { lyxose }\end{array}$ & 41.2 & 54.3 & 96.6 \\
\hline
\end{tabular}

[a] Reaction conditions: $T=333 \mathrm{~K}$, [arabinose, xylose] $=0.28 \mathrm{M}$, (arabinose, xylose) $/ \mathrm{Mo}=50, t=30 \mathrm{~min}$. [b] Equilibrium conversion obtained at $t=$ $16 \mathrm{~h}$. [c] Based on Mo. [d] Selectivity to ribose or lyxose from arabinose and xylose, respectively.

carbon has been reported to display the highest activity in this reaction, although its selectivity to mannitol is limited by the sustained formation of the epimeric alcohol sorbitol. A more selective process has been attained by alloying this element with other metals. ${ }^{[17]}$ To choose the most suitable material, we thus prepared a $5 \mathrm{wt} \% \mathrm{Ru} / \mathrm{C}$ catalyst as well as bimetallic systems comprising the same amount of Ru and $1 \mathrm{wt} \% \mathrm{Sn}, \mathrm{Cr}, \mathrm{La}$, or Pd by incipient wetness. As shown in Table 3, the actual

\begin{tabular}{|c|c|c|c|c|c|}
\hline Catalyst & $\begin{array}{l}\mathrm{Ru}^{[\mathrm{a}]} \\
{[\mathrm{wt} \%]}\end{array}$ & $\begin{array}{l}M^{[\mathrm{b}]} \\
{[\mathrm{wt} \%]}\end{array}$ & $\begin{array}{l}V_{\text {pore }}^{[c]} \\
{\left[\mathrm{mLg}^{-1}\right]}\end{array}$ & $\begin{array}{l}S_{B E[}^{[d]} \\
{\left[\mathrm{m}^{2} \mathrm{~g}^{-1}\right]}\end{array}$ & $\begin{array}{l}D_{\mathrm{CO}}{ }^{[\mathrm{e}]} \\
{[\%]}\end{array}$ \\
\hline $\mathrm{Ru} / \mathrm{C}$ & 4.8 & - & 0.58 & 912 & 61 \\
\hline RuSn/C & 5.1 & 1.0 & 0.61 & 956 & 54 \\
\hline $\mathrm{RuCr} / \mathrm{C}$ & 4.9 & 0.9 & 0.53 & 988 & 58 \\
\hline RuLa/C & 4.8 & 1.0 & 0.55 & 973 & 60 \\
\hline $\mathrm{RuPd} / \mathrm{C}$ & 5.0 & 1.0 & 0.57 & 934 & 67 \\
\hline
\end{tabular}

[a] ICP-OES. [b] XRF. [c] Volume of $\mathrm{N}_{2}$ adsorbed at $p / p_{0}=0.99$. [d] BET method. [e] Ru dispersion determined by $\mathrm{CO}$ pulse chemisorption.

metal loadings were determined to be close to the nominal values. The porous properties of the support were not substantially modified upon deposition of the active phase. No reflections attributed to any of the metals were observed in the XRD patterns of the solids (Figure S1 b), which was indicative of high dispersion. The latter was determined for $\mathrm{Ru}$ to be in the $54-67 \%$ range on the basis of CO chemisorption. Additionally, TEM analysis of Ru/C (Figure $3 \mathrm{a}$ ) visualized very small metallic particles with diameters less than $5 \mathrm{~nm}$.

Testing of these catalysts in the hydrogenation of fructose surprisingly revealed that the presence of any of the second metals did not improve the mannitol/sorbitol ratio (Figure $3 \mathrm{~b}$ ) and reduced the activity. The discrepancy between our data and earlier evidence may originate from the different reaction conditions applied. ${ }^{[17]}$ On the basis of these results, further studies were conducted over the simple Ru/C catalyst. Firstly, the dependence of mannitol selectivity on the temperature and hydrogen pressure was explored. Although very different operating conditions were investigated (Figure $3 \mathrm{c}$ ), only slight changes in the mannitol selectivity were observed, which was the highest below $0.7 \mathrm{MPa}$ and at $313-343 \mathrm{~K}$. On the other hand, the conversion increased monotonously with the tem- 
(a)
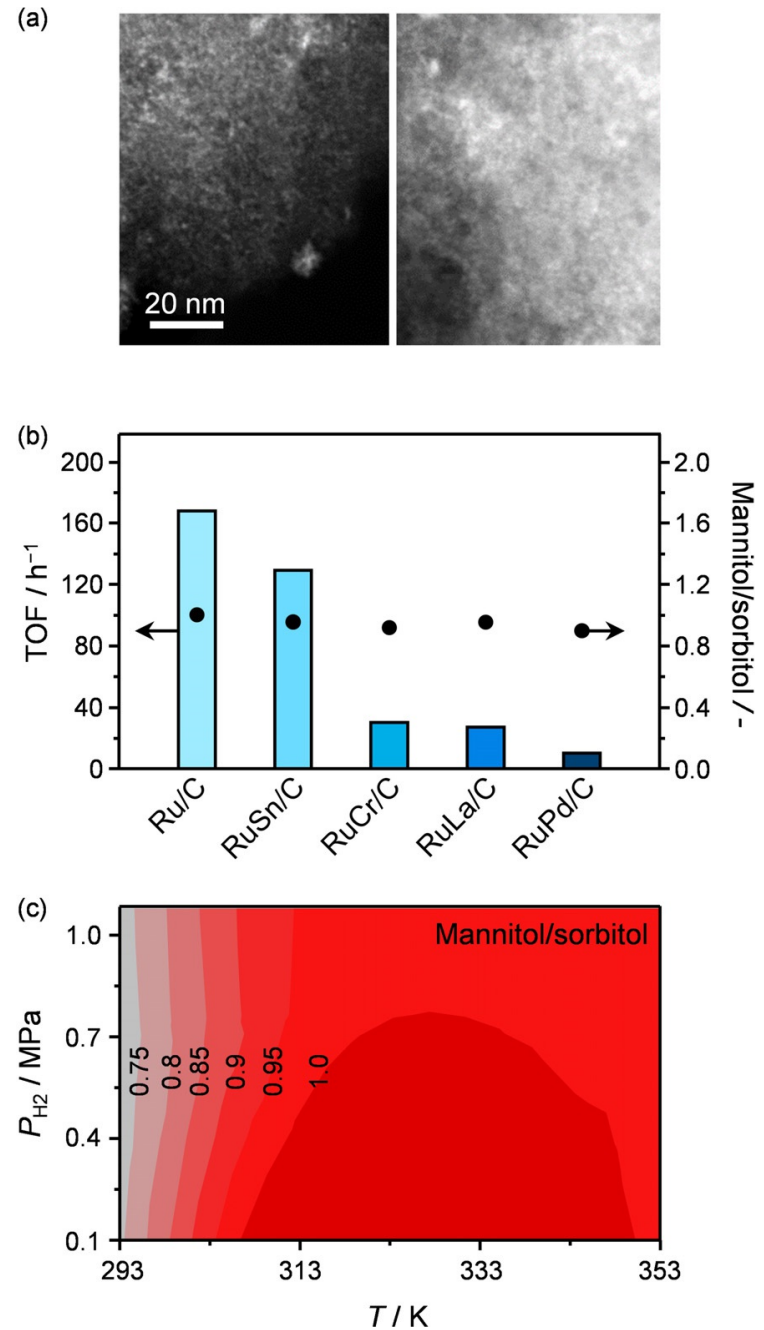

Figure 3. (a) HAADF-STEM micrographs for the fresh (left) and used (right) $\mathrm{Ru} / \mathrm{C}$ catalyst. (b) Effect of metal modifiers on the fructose hydrogenation activity and selectivity to mannitol of Ru/C at $333 \mathrm{~K}$. The TOF was calculated on the basis of the exposed Ru sites. (c) Mannitol/sorbitol ratio upon fructose hydrogenation versus temperature and $\mathrm{H}_{2}$ pressure.

perature or the pressure (Figure S2). Subsequent testing of the hydrogenation of the mixtures of epimers was conducted in these ranges. Batch experiments performed at low conversion levels proved that the hydrogenation of one of the two epi-
Table 4. Reaction rates for the hydrogenation of glucose/mannose, xylose/lyxose, and arabinose/ribose on $\mathrm{Ru} / \mathrm{C}^{[\mathrm{a}]}$

\begin{tabular}{|lll|}
\hline Sugar mixture $(i / j)$ & $\begin{array}{l}\mathrm{TOF}_{i} \\
{\left[\mathrm{~h}^{-1}\right]}\end{array}$ & $\begin{array}{c}\mathrm{TOF}_{j} \\
{\left[\mathrm{~h}^{-1}\right]}\end{array}$ \\
\hline glucose/mannose & 13.4 & 25.1 \\
xylose/lyxose & 10.9 & 23.6 \\
arabinose/ribose & 19.1 & 48.1
\end{tabular}

[a] Reaction conditions: $T=333 \mathrm{~K}$, [glucose, xylose, arabinose $]=[\mathrm{man}-$ nose, lyxose, ribose $]=0.14 \mathrm{M}$, (glucose + mannose, xylose + lyxose, arabinose + ribose) $/ \mathrm{Ru}=100, t=15 \mathrm{~min}, P_{\mathrm{H}_{2}}=0.1 \mathrm{MPa}$.

mers proceeded more readily for all mixtures (Table 4). In particular, mannose, lyxose, and ribose were reduced to the corresponding sugar alcohols 2-3 times faster than their isomers. To further investigate this effect, kinetic tests were performed to derive the apparent activation energies for the conversion of the two hexoses. On the basis of the Arrhenius plots (Figure $4 \mathrm{a}$ ), the hydrogenation of mannose was found to be less impeded than that of glucose by $6.5 \mathrm{~kJ} \mathrm{~mol}^{-1}$.

This significant difference implies that, assuming first-order reaction kinetics, the maximum theoretical mannitol/sorbitol formation rate ratio is between 4 and 2.5 in the $293-373 \mathrm{~K}$ range (Figure $4 \mathrm{~b}$ ), as confirmed by the experimental data. This hints at the possibility of overcoming, after adequate engineering of the catalyst and the process, the approximately 1:1 sugar ratio obtained upon epimerization. Ultimately, the twostep process would thus enable an overall higher selectivity than that obtained by direct hydrogenation of the typically rare ketose. The analogous differences in the reaction rate observed during the hydrogenation of mixtures of aldopentose epimers likely find the same origin. Indeed, the stereochemical configuration of the two carbon atoms in proximity to the carbonyl group is the same for glucose, arabinose, and xylose $(2 R, 3 S)$ and for mannose, ribose, and lyxose $(2 S, 3 S)$, which exhibited slower and faster reaction rates, respectively.

The stability of the hydrogenation catalyst was evaluated in $24 \mathrm{~h}$ runs (Figure $5 \mathrm{a}-\mathrm{c}$ ). The catalyst lost $15-35 \%$ of its original activity in the conversion of the three mixtures. This evidence is in line with previous hydrogenation studies for which $\mathrm{Ru} / \mathrm{C}$ catalysts were used and for which the deactivation was ascribed to fouling or poisoning by adsorption of trace amounts
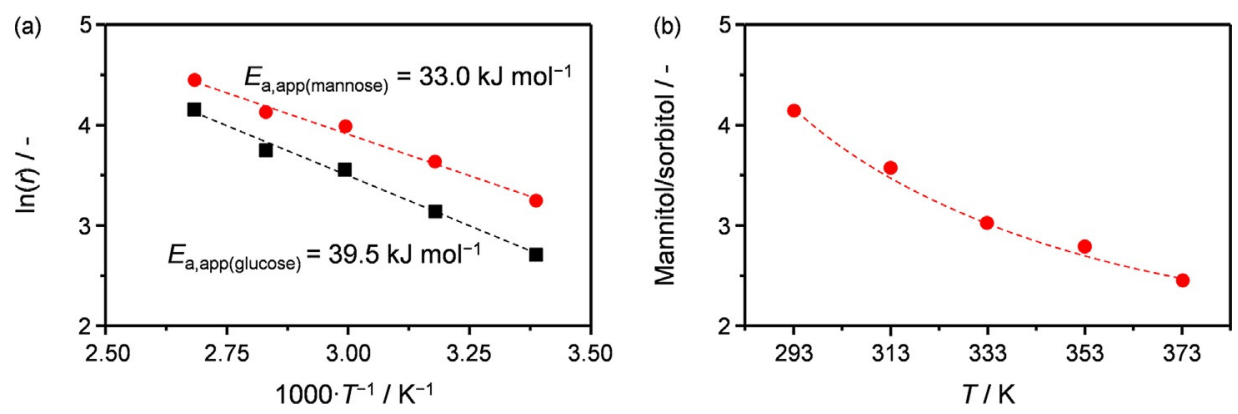

Figure 4. (a) Arrhenius plot and the corresponding apparent activation energies for the hydrogenation of glucose and mannose over Ru/C. (b) Mannitol/sorbitol ratio versus temperature. The red line represents the theoretical values obtained from the activation energies. 

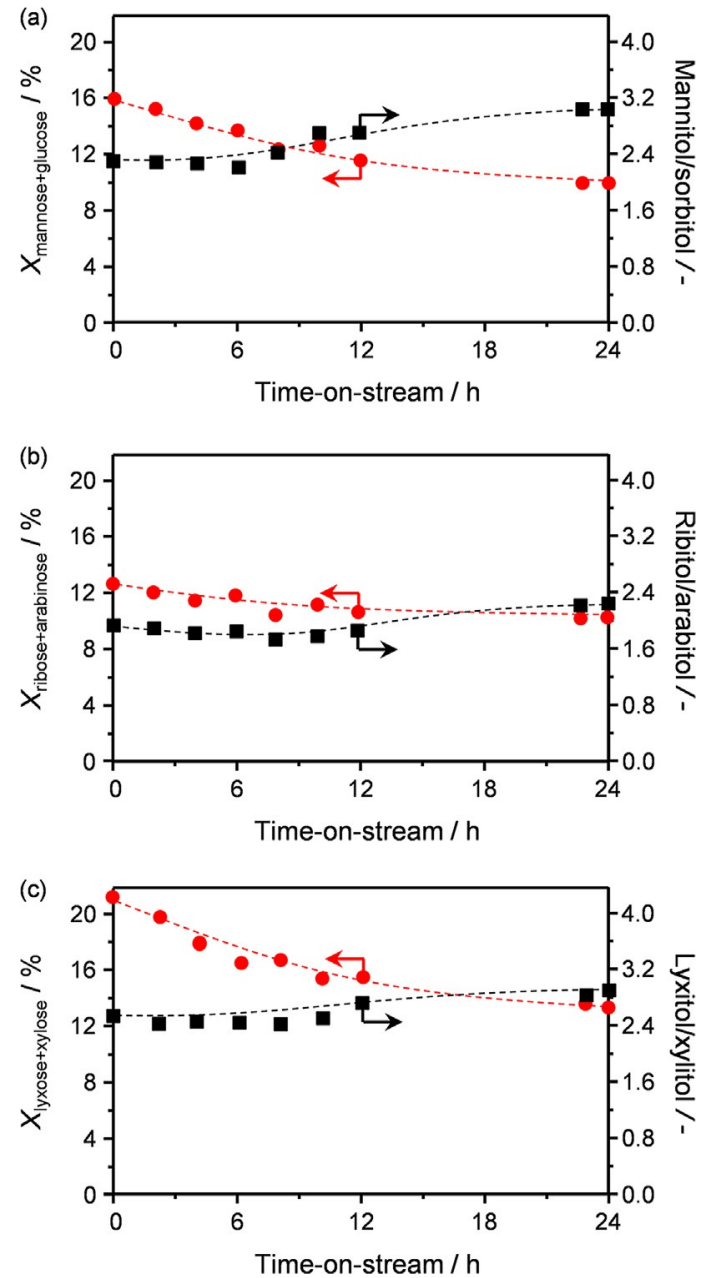

Figure 5. Total conversion and ratio of sugar alcohols for the hydrogenation of (a) glucose/mannose, (b) ribose/arabinose, and (c) lyxose/xylose mixtures over $\mathrm{Ru} / \mathrm{C}$ at $333 \mathrm{~K}$

of gluconic/mannonic acids formed upon exposure of the starting saccharide solutions to air. ${ }^{[29]}$ An increase in the sugar alcohol ratio was observed in parallel to the decrease in activity. This is explained by the fact that, at higher conversion levels, the concentration of the slower reacting sugar is greater than that of the faster reacting one, which lowers the difference between their actual hydrogenation rates. Aiming at a more robust process, the catalyst could be periodically washed with a suitable solvent to restore its functionality or the liquid feed could be isolated under an inert atmosphere. Additionally, the sugar alcohol ratio was slightly altered in favor of mannitol, ribitol, and arabitol with time on stream. This is explained by the fact that the more reactive sugar is consumed more rapidly than the more inert epimer. Accordingly, keeping a low conversion level ensures a higher amount of mannose, ribose, and lyxose available as substrates, which promotes the formation of the desired alcohol.

DFT was applied to unravel the molecular reason for the different reactivities of the sugars and epimers towards hydrogenation by considering the case of glucose and mannose. First, the adsorption modes of these two saccharides on a metallic $\mathrm{Ru}(0001)$ surface were studied. In the liquid phase, their cyclic $\alpha$ and $\beta$ forms dominate over their open structures (denoted as $o$-glucose and $o$-mannose). Specifically, $\alpha$-glucose, $\beta$-glucose, $\alpha$-mannose, and $\beta$-mannose are more abundant $(33,66,66$, and $33 \%$, respectively) than o-glucose and o-mannose, which only account for less than $1 \%$ each. ${ }^{[30]}$ Nevertheless, both configurations were considered. The adsorption geometries obtained in the screening are reported in Figure S3, and the adsorption energies relative to the most stable configuration are reported in Table S2. The calculated energy of water solvation for $\beta$-glucose $\left(-87.8 \mathrm{~kJ} \mathrm{~mol}^{-1}\right)$ is in reasonable agreement with previous reports $\left(-77.2 \mathrm{~kJ} \mathrm{~mol}^{-1}\right){ }^{[31]}$

Thereafter, activation energies for the hydrogenation reactions were computed. Those obtained for the linear forms (Table S3 and Figure S4) are not able to explain the difference in rate determined experimentally, probably because of their negligible concentration in solution. The results for the ring structures (Figure 6) show that the $\alpha$ forms have lower adsorption energies than the $\beta$ forms for both glucose ( -97.4 vs. $\left.-92.6 \mathrm{~kJ} \mathrm{~mol}^{-1}\right)$ and mannose $\left(-124.5 \mathrm{vs} .-109.0 \mathrm{~kJ} \mathrm{~mol}^{-1}\right)$ with energy differences of 4.8 and $15.5 \mathrm{~kJ} \mathrm{~mol}^{-1}$, respectively. Moreover, they indicate that both $\alpha$ - and $\beta$-mannose adsorb on the catalyst more strongly than $\alpha$ - and $\beta$-glucose. The different stereochemical configuration of the $\mathrm{C} 2$ in mannose $(S)$ relative to that in glucose $(R)$ increases the number of sugar interactions

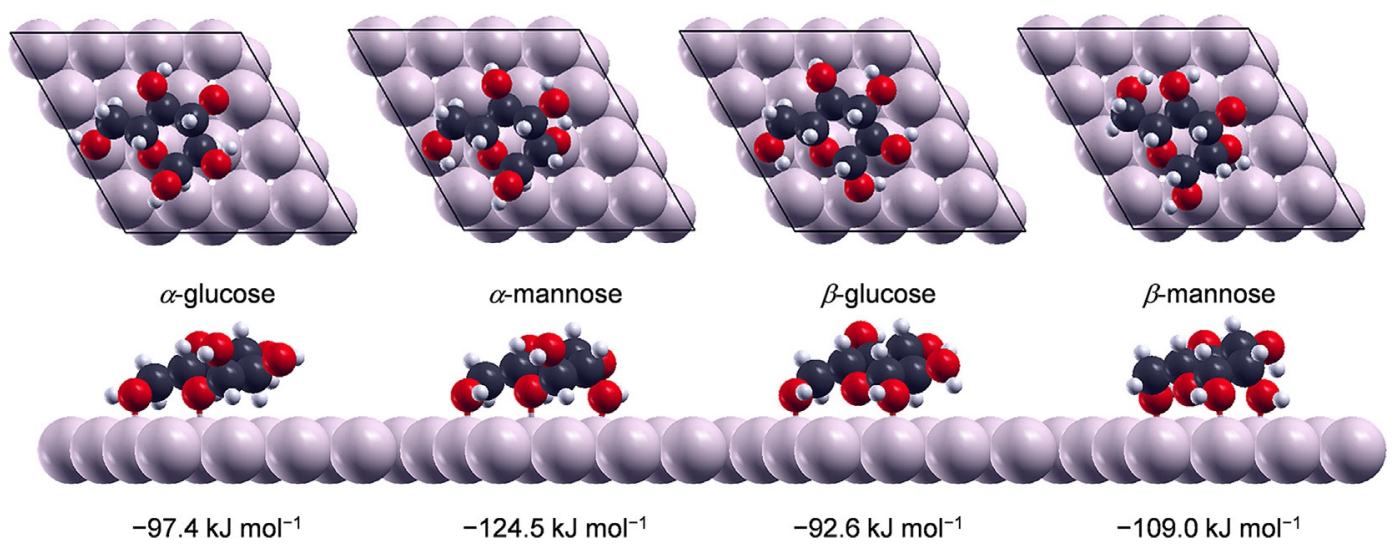

Figure 6. Adsorption structures and binding energies of the $\alpha$ and $\beta$ forms of glucose and mannose on $\mathrm{Ru}(0001)$. 
with $\mathrm{Ru}$ through $\mathrm{O}$ atoms by one, which, as reported earlier, is the primary contributor to adsorption. ${ }^{[32]}$ After interaction with the metal, the molecules can react with water, which leads to o-glucose and o-mannose, or with adsorbed $\mathrm{H}$ atoms. For both glucose and mannose, the transition states relative to ring opening $^{[33]}$ and the following hydrogenation reaction were initially studied in the absence of water (Table 5). The energy barriers for ring opening ( $\mathrm{C}-\mathrm{O}$ cleavage, see Scheme 2$)$ are com-

\begin{tabular}{|c|c|c|c|c|c|}
\hline \multirow[t]{2}{*}{ Species } & \multicolumn{5}{|c|}{$E_{\mathrm{a}}\left[\mathrm{kJ} \mathrm{mol}^{-1}\right]$} \\
\hline & $\mathrm{C}-\mathrm{O}$ & $\mathrm{C} 1+\mathrm{H}$ & $\mathrm{O} 5+\mathrm{H}$ & $\mathrm{C}-\mathrm{O}\left(\mathrm{H}_{2} \mathrm{O}\right)$ & $\mathrm{C}+\mathrm{H}$ \\
\hline$\alpha$-glucose & 193.9 & 297.2 & 321.3 & 194.9 & - \\
\hline$\beta$-glucose & 150.5 & 260.5 & 235.4 & 95.5 & 116.7 \\
\hline$\alpha$-mannose & 144.7 & 162.1 & 247.0 & 131.2 & 91.7 \\
\hline$\beta$-mannose & 174.6 & 250.9 & 272.1 & 159.2 & - \\
\hline
\end{tabular}

parably high for $\beta$-glucose and $\alpha$-mannose (150.5 and $144.7 \mathrm{~kJ} \mathrm{~mol}^{-1}$, respectively) and are lower than the energy barriers of the other two isomers, $\alpha$-glucose $\left(193.9 \mathrm{~kJ} \mathrm{~mol}^{-1}\right)$ and $\beta$-mannose $\left(174.6 \mathrm{~kJ} \mathrm{~mol}^{-1}\right)$. Regarding hydrogenation, two sites are present that can accept $\mathrm{H}$ atoms ( $\mathrm{C} 1$ and 05$)$. For both glucose and mannose, 05 hydrogenation is associated with higher barriers than $\mathrm{C} 1$ hydrogenation. The energy demand of the latter is lower for $\alpha$ - and $\beta$-mannose (162.1 and $205.9 \mathrm{~kJ} \mathrm{~mol}^{-1}$ ) than for $\alpha$ - and $\beta$-glucose (297.2 and $260.5 \mathrm{~kJ} \mathrm{~mol}^{-1}$ ), which points to the positive effect of the additional interaction between the surface and the $\mathrm{C} 2$ or $\mathrm{C} 1$ hydrogenation. On the basis of the values obtained, it appears that the different configuration of $\mathrm{C} 2$ determines that the reactive conformation is $\alpha$ in the case of mannose and $\beta$ in the case of glucose. In view of the distance between C2 and 05, the impact of $\mathrm{Ru}-\mathrm{C} 2$ bonding is not effective in lowering the $\mathrm{O} 5$ hydrogenation barrier. Additional theoretical simulations were performed considering the presence of a water molecule to attain a more realistic representation of the catalytic system. The results (Figure 7) indicate that the presence of the solvent promotes ring opening by lowering the energy demand by 55.0 and $5.9 \mathrm{~kJ} \mathrm{~mol}^{-1}$ for $\beta$-glucose and $\alpha$-mannose, respectively. The beneficial impact of water is twofold: it provides an $\mathrm{H}$ atom for $\mathrm{O} 5$ protonation and stabilizes the transition states by hydrogen bonding (Scheme 2). In spite of a lower ring-opening barrier, the activation energy for $\mathrm{C} 1$ hydrogenation is higher for o-glucose than for o-mannose (116.7 vs. $\left.91.7 \mathrm{~kJ} \mathrm{~mol}^{-1}\right)$. Hence, the rate-determining steps are $\mathrm{C} 1$ hydrogenation for $\beta$ glucose and ring opening for $\alpha$-mannose.

To explain the experimental results, a kinetic model based on Langmuir competitive adsorption and transition state theories was built. ${ }^{[34]}$ The coverage of surface species was estimated by Equation (1) and (2):

$\theta_{i-A}=\frac{K_{i-A}^{\text {ads }} \cdot[i-A]}{1+\sum_{i} K_{i-A}^{\text {ads }} \cdot[i-A]}$

for which

$K_{i-A}^{\mathrm{ads}}=\exp \left(\frac{-\Delta G_{i-A}^{\mathrm{ads}}}{R T}\right)$

and $K_{i-A}^{\text {ads }}$ is the equilibrium constant for the adsorption of $i-A$, $\Delta \mathrm{G}_{\mathrm{i}-\mathrm{A}}^{\mathrm{ads}}$ is the Gibbs energy of the adsorption, and $[i-A]$ is the concentration of glucose or mannose in the form $i$ ( $\alpha$ or $\beta$ ) in solution. The expression for the hydrogenation rate is [Eq. (3)]:

$r_{i-A}=k_{i-A} \cdot \theta_{i-A} \cdot \theta_{H}=A_{i-A}\left(\frac{-E_{i-A}^{A}}{R T}\right) \cdot \theta_{i-A} \cdot \theta_{H}$

in which $k_{i-A}$ is the rate coefficient, $A_{i-A}$ is the pre-exponential factor for the hydrogenation reaction, $E_{i-A}^{a}$ is the energy barrier for the rate-limiting process (i.e., ring opening or hydrogenation), and $\theta_{\mathrm{H}}$ is the surface coverage of $\mathrm{H}$ (which is treated as a constant; i.e., $\theta_{H}=1$ ). According to the analysis of the transition states, only $\beta$-glucose and $\alpha$-mannose would be hydro-

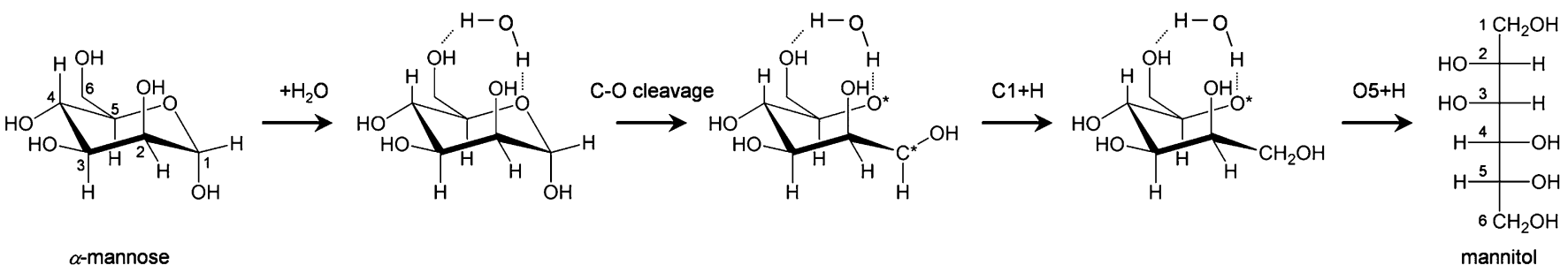

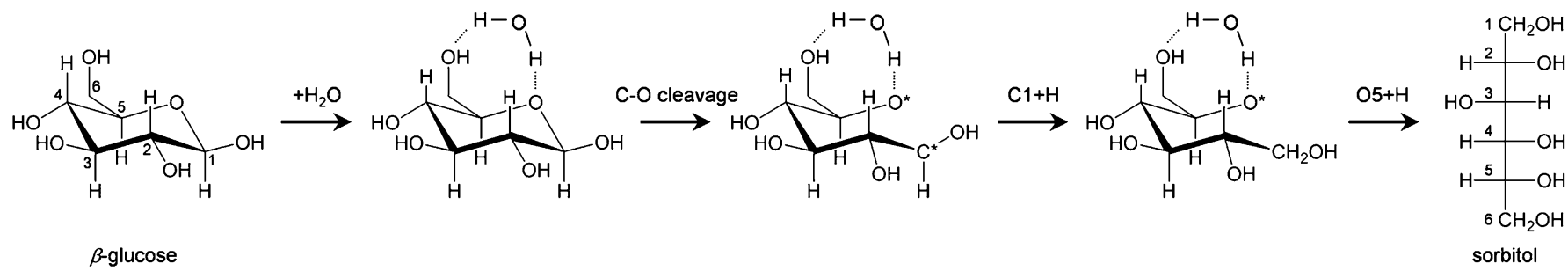

Scheme 2. Reaction mechanisms for the hydrogenation of $\alpha$-mannose to mannitol (top) and $\beta$-glucose to sorbitol (bottom). 


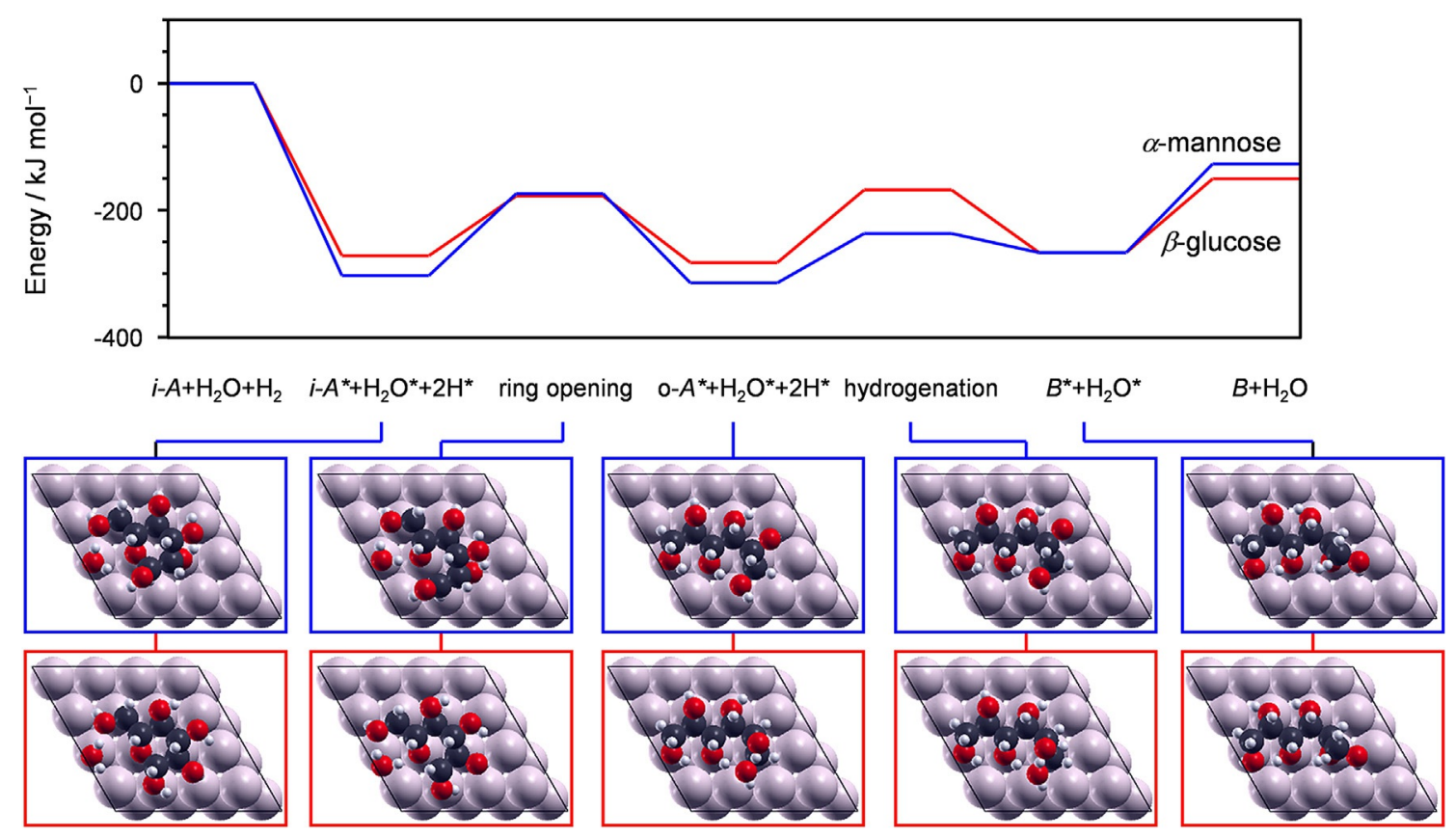

Figure 7. Energy profiles for the hydrogenation of $\beta$-glucose to sorbitol (red) and of $\alpha$-mannose to mannitol (blue) and the corresponding structures calculated over the Ru(0001) surface.

genated with lower energy barriers. The most energy-demanding steps are different for $\alpha$-mannose (step 2) and $\beta$-glucose (step 3), as shown in Table 6. The relative rates for glucose and mannose hydrogenation can be written as follows, for which $\mathrm{C}-\mathrm{O}$ refers to the ring-opening reaction and $\mathrm{C}+\mathrm{H}$ to $\mathrm{C} 1$ hydrogenation [Eq. (4)]:

$\frac{r_{\alpha-\text { mannose }}}{r_{\beta-\text { glucose }}} \approx \frac{r_{\alpha-\text { mannose }, \mathrm{C}-\mathrm{O}}}{r_{\beta-\text { glucose } \mathrm{C}+\mathrm{H}}}=\frac{k_{\alpha-\text { mannose }, \mathrm{C}-\mathrm{O}} \cdot \theta_{\alpha-\text { mannose }}}{k_{\beta-\text { glucose } \mathrm{C}+\mathrm{H}} \cdot \theta_{o-\text { glucose }} \cdot \theta_{H}}$
$\approx \frac{k_{\alpha-\text { mannose }, \mathrm{C}-\mathrm{O}} \cdot \theta_{\alpha-\text { mannose }}}{k_{\beta-\text { glucose } \mathrm{C}+\mathrm{H}} \cdot K_{\beta-\text { glucose }}^{\mathrm{C}-\mathrm{O}} \cdot \theta_{\beta-\text { glucose }}}$
$=\exp \left(-\frac{E_{\alpha-\text { mannose }}^{\mathrm{a}}+\Delta G_{\alpha-\text { mannose }}^{\text {ads }}-E_{\beta-\text { glucose }}^{\mathrm{a}}-\Delta G_{\beta-\text { glucose }}^{\text {ads }}}{R T}\right)$
$\cdot \frac{[\alpha-\text { mannose }]}{K_{\beta-\text { glucose }}^{\mathrm{C}-O} \cdot[\beta-\text { glucose }]}$
$=\frac{1}{K_{\beta-\text { glucose }}^{C-O}} \exp \left(-\frac{E_{\alpha-\text { mannose }}^{\text {a }}+\Delta G_{\alpha-\text { mannose }}^{\text {ads }}-E_{\beta-\text { glucose }}^{\text {a }}-\Delta G_{\beta-\text { glucose }}^{\text {add }}}{R T}\right)$

in which $\theta_{\text {o-glucose }}$ is the surface coverage of open glucose and $K_{\beta-\text { glucose }}^{\mathrm{C}-\mathrm{O}}$ is the equilibrium constant of the $\beta$-glucose ringopening reaction. Given that mannose can be practically obtained from glucose by an equilibrium-limited epimerization reaction with [glucose]/[mannose] $\approx 2$ [Eq. (5)]:

$\frac{[\alpha-\text { mannose }]}{[\beta-\text { glucose }]}=\left(\frac{2}{3}[\right.$ mannose $\left.]\right) /\left(\frac{1}{3}[\right.$ glucose $\left.]\right) \approx 1$

Using the calculated adsorption and activation energies, the ratio of reaction rates between $\alpha$-mannose and $\beta$-glucose was
Table 6. Steps for the hydrogenation of $\alpha$-mannose and $\beta$-glucose on $\mathrm{Ru}(00001)^{[a]}$

\begin{tabular}{|c|c|c|}
\hline Step & $\alpha$-Mannose & $\beta$-Glucose \\
\hline 1 & $\alpha$-mannose $+^{*} \leftrightarrow \alpha$-mannose ${ }^{*}$ & $\beta$-glucose $+^{*} \leftrightarrow \beta$-glucose ${ }^{*}$ \\
\hline 2 & $\alpha$-mannose ${ }^{*} \rightarrow o-$ mannose ${ }^{*[a]}$ & $\beta$-glucose $e^{*} \leftrightarrow o$-glucose $e^{*[a]}$ \\
\hline 3 & o-mannose ${ }^{*}+\mathrm{H}^{*} \leftrightarrow$ mannitol ${ }^{*}+{ }^{*}$ & o-glucose ${ }^{*}+\mathrm{H} \rightarrow$ sorbitol $^{*}+{ }^{*}$ \\
\hline 4 & mannitol* ${ }^{*}$ mannitol $+^{*}$ & sorbitol $^{*} \leftrightarrow$ sorbitol $+^{*}$ \\
\hline
\end{tabular}

[a] o-Mannose* and o-glucose* correspond to the linear structures of mannose and glucose, respectively.

estimated to be approximately 11 . Considering that the DFT simulations were performed with several approximations, including the use of only one adsorption configuration for the reactants and the use of a single molecule of water in the ringopening step and excluding solvation effects when the molecule was adsorbed, the qualitative agreement between this estimate and the value derived experimentally (2.7) is remarkable. In this perspective, even the order of magnitude of the relative activity is meaningful. Notice that the error associated with the difference in the computed and experimentally estimated energy barriers corresponds to only $0.04 \mathrm{eV}$.

\section{Process design}

The identification of efficient epimerization and hydrogenation catalysts suitable for use under flow conditions opens the door to realize a continuous two-step process for the conversion of glucose into mannitol. To this end, the configuration of the catalytic bed(s) and the operation temperature comprise the main parameters to be tuned. Initially, the performance of a single bed constituted by a physical mixture of the two cata- 
lysts was evaluated. In this case, the temperature was set to $363 \mathrm{~K}$, as the epimerization catalyst Cs-HPA/C cannot produce a high concentration of mannose under milder conditions (Figure $2 \mathrm{a}$ ), as discussed before. At the initial stages of the reaction, the mannitol/sorbitol ratio was approximately 1 (Figure 8 a and Table S4). This is a remarkable result, as the value is equivalent to that obtained in the reduction of fructose. ${ }^{[11]}$ Still,
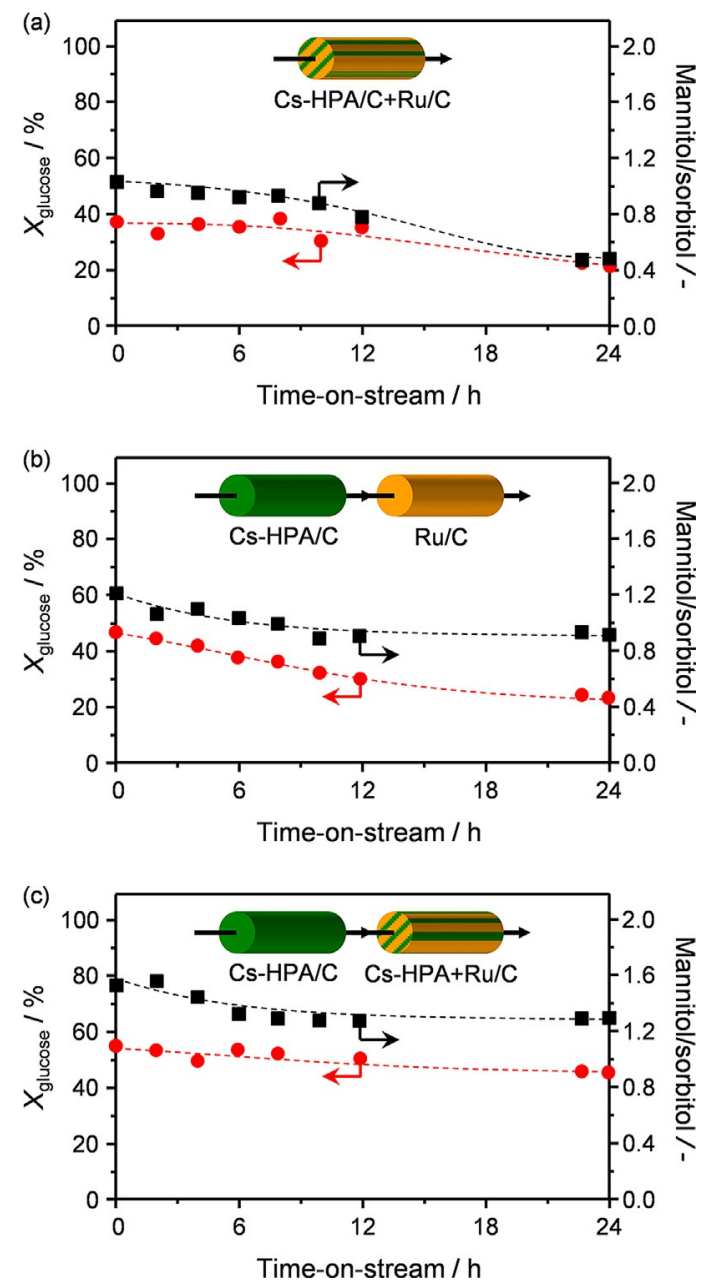

Figure 8. Glucose conversion and mannitol/sorbitol ratio by using different reactor configurations: (a) a single reactor with a mixture of Cs-HPA/C and $\mathrm{Ru} / \mathrm{C}$ at $363 \mathrm{~K}$, (b) two series reactors containing Cs-HPA/C at $363 \mathrm{~K}$ and $\mathrm{Ru} / \mathrm{C}$ at $333 \mathrm{~K}$, respectively, and (c) two series reactors containing Cs-HPA/C at $363 \mathrm{~K}$ and a mixture of $\mathrm{Cs}-\mathrm{HPA} / \mathrm{C}$ and $\mathrm{Ru} / \mathrm{C}$ at $333 \mathrm{~K}$, respectively.

during the course of the reaction, the glucose conversion decreased by approximately $30 \%$ and the mannitol/sorbitol ratio was reduced to approximately 0.4 . The two observations are likely related, that is, the lower amount of mannitol formed as a result of the deactivation of the epimerization catalyst caused a reduction in the mannitol production rate, similar to the case of the hydrogenation of equimolar mixtures of epimers (Figure 5). Moreover, the hydrogenation catalyst was operated at an excessively high temperature, which could trigger additional deactivation phenomena (Figure 4 b). Hence, an improved process was achieved by separating the epimerization and the hydrogenation catalysts into two distinct reactors. In this case, the temperature applied to the latter could be lowered by $50 \mathrm{~K}$, which theoretically should enable an increase in the mannitol/sorbitol ratio by approximately $40 \%$. In this configuration, the polyols ratio was raised to 1.2 (Figure $8 \mathrm{~b}$ and Table S4) and, owing to the milder conditions in the second reactor, remained significantly more stable than in the first scenario. The glucose conversion and the deactivation rate were similar to those observed in the previous case. Still, further optimization of the process was envisaged on the basis of the following reasoning. Even if the hydrogenation catalyst is operated at its optimal temperature, concentration gradients will develop along the bed. Specifically, the portion of catalyst located closer to the reactor outlet will be contacted with a solution containing much less mannose, as a great part of it will have already been converted over the fraction of catalyst placed at the beginning of the bed. Thus, the formation of mannitol will decrease along the bed. Consequently, a third configuration was explored, in which the first reactor was dedicated solely to epimerization at high temperature $(363 \mathrm{~K})$ and the second reactor contained a mixture of $\mathrm{Ru} / \mathrm{C}$ and $\mathrm{Cs}-\mathrm{HPA} / \mathrm{C}$, operated at a lower temperature $(333 \mathrm{~K})$. In this way, the mannose concentration, which decreases during the course of the hydrogenation reaction, could be restored continuously. Remarkably, the mannitol/sorbitol ratio increased even further to approximately 1.6 (Figure $8 \mathrm{c}$ and Table S4). Additionally, the glucose conversion was constant over 1 day, possibly thanks to the overall increased mass of the Cs-HPA/C catalyst. In line with that observed in the second process design, the mannitol selectivity remained more stable over the same timeframe as well.

This continuous chemocatalytic technology stands as a promising alternative to the batch biocatalytic preparation of sugar alcohols. In fact, it allows for higher operational flexibility and for reduced waste production, as sugar feeds featuring a less constrained composition and a higher concentration can be applied. Moreover, it is foreseen that the continuous-flow reactors can be scaled up easily and that energy can be saved through heat integration between units, that is, heat recovered from the reactors can produce energy to operate the separation units. These elements are expected to substantially lower the economic and environmental footprint of the production of polyols.

\section{Conclusions}

We successfully demonstrated a chemocatalytic continuous process for the preparation of sugar alcohols from the epimers of their corresponding aldoses. Targeting the preparation of mannitol from glucose, ribitol from arabinose, and arabinol from xylose, an improved epimerization catalyst was initially developed. In this regard, activated carbon was uncovered as a support offering higher stability to the immobilized phosphomolybdic acid phase. Ion exchange of the heteropolyacid from the protonic form to the cesium form limited its large solubility even further, which led to partial retention of the original catalyst performance even after $24 \mathrm{~h}$ on stream. Thereafter, the hydrogenation of mixtures of epimers over a ruthenium 
catalyst was studied. Interestingly, the reaction rate was found to be dependent on the stereochemical configuration of the sugar. Density functional theory simulations showed that the latter strongly influences the adsorption and activation energies for the hydrogenation of the carbon atom. Finally, the process design was optimized through the selection of the most efficient reactor configuration. The use of two series flow reactors brought considerable advantages with respect to a single reactor. In particular, the mannitol yield was maximized if the first reactor contained the epimerization catalyst and the second reactor contained a mixture of the epimerization and hydrogenation solids. In addition to improved selectivity, the possibility of optimizing the operation temperature in each reactor led to a remarkable increase in catalyst stability. Overall, this process enables a rather straightforward method for the preparation of rare polyols starting from widely available sugars. The use of a fully chemocatalytic technology, in contrast to fermentation, shall grant reduced waste production, continuous operation, easier scalability, and, possibly, improved ecological and economic metrics.

\section{Experimental Section}

\section{Catalyst preparation}

Hydrated phosphomolybdic acid (Sigma-Aldrich, >99\%, denoted $\mathrm{H}-\mathrm{HPA}$ ) and $\mathrm{MoO}_{3}$ (Sigma-Aldrich, 99.5\%) were used as received. Silver and cesium phosphomolybdates were prepared by coprecipitation of $\mathrm{H}-\mathrm{HPA}\left(0.01 \mathrm{~m}\right.$ aqueous solution) with $\mathrm{AgNO}_{3}$ ( $\mathrm{ABCR}$, 99.9\%) and $\mathrm{CsNO}_{3}$ (Acros Organics, 99.99\%), respectively, which were added in $50 \%$ molar excess. The solids were separated by filtration, washed with deionized water $(\approx 100 \mathrm{~mL}$ per gram of dried material), and dried ( $338 \mathrm{~K}, 16 \mathrm{~h}$ ). They were labeled Ag-HPA and Cs-HPA. Supported HPA catalysts were prepared by using silica (Sipernat 120, code $\mathrm{SiO}_{2}$ ), an anionic ion-exchange resin (Amberlyst A26, Sigma-Aldrich, code IER), and granulated activated carbon (Norit Cabot RX 1.5 Extra, 0.2-0.4 mm sieve fraction, code C). The supports $(2.0 \mathrm{~g})$ were added to a solution of H-HPA $(0.5 \mathrm{~g})$ in water $(50 \mathrm{~mL})$, and the suspension was magnetically stirred for $2 \mathrm{~h}$. Thereafter, the solids were separated by filtration, washed with deionized water $(\approx 100 \mathrm{~mL}$ per gram of dried support), and dried $(338 \mathrm{~K}, 16 \mathrm{~h})$. They were labeled $\mathrm{H}-\mathrm{HPA} / \mathrm{SiO}_{2}, \mathrm{H}-$ HPA/IER, and H-HPA/C. Two additional C-supported samples (Ag$\mathrm{HPA} / \mathrm{C}$ and $\mathrm{Cs}-\mathrm{HPA} / \mathrm{C}$ ) were produced through the same procedure by adding $\mathrm{AgNO}_{3}$ or $\mathrm{CsNO}_{3}$ to the suspension. A supported $5 \mathrm{wt} \%$ $\mathrm{Ru} / \mathrm{C}$ catalyst was synthesized by impregnation of the $C$ support with an aqueous solution of $\mathrm{RuCl}_{3} \cdot \mathrm{H}_{2} \mathrm{O}(\mathrm{ABCR}, 99.9 \%)$, followed by drying $(338 \mathrm{~K}, 16 \mathrm{~h})$ and reduction in hydrogen flow $\left(20 \mathrm{vol} \% \mathrm{H}_{2} /\right.$ $\left.\mathrm{N}_{2}, 100 \mathrm{~mL} \mathrm{~min}{ }^{-1}, 723 \mathrm{~K}\right)$. Bimetallic $5 \mathrm{wt} \% \mathrm{Ru} / 1 \mathrm{wt} \% \mathrm{M} / \mathrm{C}$ catalysts $(\mathrm{M}=\mathrm{Sn}, \mathrm{Cr}$, La, or $\mathrm{Pd}$ ) were prepared through the same method by additionally using $\mathrm{SnSO}_{4}, \mathrm{Cr}\left(\mathrm{NO}_{3}\right)_{3} \cdot 9 \mathrm{H}_{2} \mathrm{O}$ (Sigma-Aldrich, 99\%), $\mathrm{LaCl}_{3}(\mathrm{ABCR}, 99.9 \%)$, or $\mathrm{PdCl}_{2}(\mathrm{ABCR}, 99.9 \%)$ as the precursor of the second metal upon impregnation.

\section{Catalyst characterization}

The Mo and Ru contents in the catalysts were determined by inductively coupled plasma optical emission spectroscopy (ICP-OES) by using a Horiba Ultra 2 instrument equipped with a photomultiplier tube detector. The Sn, Cr, La, and Pd contents and the Mo/P ratio were determined by X-ray fluorescence (XRF) spectroscopy by using an EDAX Orbis Micro-XRF analyzer equipped with a Rh source operated at a voltage of $35 \mathrm{kV}$ and a current of $500 \mu \mathrm{A}$. Powder X-ray diffraction (XRD) was performed by using a PANalytical X'Pert PRO-MPD diffractometer with Ni-filtered $\mathrm{CuK}_{\alpha}$ radiation $(\lambda=0.1541 \mathrm{~nm})$, acquiring data in the $2 \theta=5-70^{\circ}$ range with a step size of $0.05^{\circ}$ and a counting time of $8 \mathrm{~s}$ per step. $\mathrm{N}_{2}$ sorption at $77 \mathrm{~K}$ was conducted by using a Micromeritics TriFlex analyzer. Prior to the measurements, the samples were degassed at $573 \mathrm{~K}$ under vacuum for $3 \mathrm{~h}$. High-angle annular dark field scanning transmission electron microscopy (HAADF-STEM) images and energy dispersive spectroscopy (EDS) elemental maps were acquired by using a FEl Talos instrument operated at $200 \mathrm{kV}$. Powdered samples were deposited on $\mathrm{Cu}$ grids. HAADF images were collected before and after the EDS measurements to corroborate the absence of morphological changes. CO chemisorption was performed by using a Micromeritics AutoChem II 2920 chemisorption analyzer. The samples were heated at $393 \mathrm{~K}$ under a He flow $\left(50 \mathrm{~mL} \mathrm{~min}{ }^{-1}\right)$ for $60 \mathrm{~min}$ and were then reduced at $523 \mathrm{~K}$ under a flow of $5 \mathrm{vol} \% \mathrm{H}_{2} /$ He $\left(20 \mathrm{~mL} \mathrm{~min}^{-1}\right)$ for $30 \mathrm{~min}$. Afterwards, $1 \mathrm{~mL}$ of $1 \mathrm{vol} \% \mathrm{CO} / \mathrm{He}$ was pulsed over the catalyst bed at $308 \mathrm{~K}$ every $4 \mathrm{~min}$. The Ru dispersion was calculated on the basis of the amount of $\mathrm{CO}$ chemisorbed, considering an adsorption stoichiometry of 1 .

\section{Catalytic testing}

Batch epimerization experiments were performed under autogenous pressure in $15 \mathrm{~mL}$, thick-walled glass vials (Ace, pressure tubes, front seal) dipped in an oil bath heated at 303-353 K. The vials were loaded with approximately $10 \mathrm{~mL}$ of a $0.28 \mathrm{M}$ aqueous solution of glucose, arabinose, or xylose. Then, the appropriate amount of molybdate-based catalyst was added to achieve a substrate/Mo molar ratio of 50 . The mixture was allowed to react under vigorous stirring for $30 \mathrm{~min}$. Thereafter, the reaction was quenched by using an ice bath, and the catalyst removed by means of a Chromafil Xtra $0.25 \mu \mathrm{m}$ syringe filter. Batch hydrogenation experiments were performed under $1.0 \mathrm{MPa}$ hydrogen (Messer, $99.999 \%$ ) in $10 \mathrm{~mL}$ autoclaves (Endeavor) at 303-393 K. The vials were loaded with $5 \mathrm{~mL}$ of a $0.28 \mathrm{M}$ fructose (SigmaAldrich, >99\%), a $0.14 \mathrm{~m}$ glucose (Sigma-Aldrich, 99.5\%)-0.14 M mannose (Sigma-Aldrich, $>99 \%$ ), a $0.14 \mathrm{M}$ arabinose (ABCR, 99\%)$0.14 \mathrm{M}$ ribose $(A B C R, 98 \%)$, or a $0.14 \mathrm{M}$ lyxose (ABCR, $99 \%)-0.14 \mathrm{M}$ xylose (Sigma-Aldrich, $>99 \%$ ) solution in deionized water. Then, the appropriate amount of $\mathrm{Ru} / \mathrm{C}$ or modified $\mathrm{Ru} / \mathrm{C}$ catalyst was added to achieve a substrate/Ru molar ratio of 100 and hydrogen was introduced. The mixture was heated to the desired reaction temperature and allowed to react under $1000 \mathrm{rpm}$ stirring for $1 \mathrm{~h}$. Then, the reaction was quenched, and the catalyst was removed by using a Chromafil Xtra $0.25 \mu \mathrm{m}$ syringe filter.

Continuous catalytic tests were performed by using a homemade flow reactor setup comprising: one, an HPLC pump (Gilson-306); two, a mass flow controller; three, stainless-steel tubular reactors (Swagelok SS-T4-S-035, o.d. $=6 \mathrm{~mm}$, i.d. $=4.6 \mathrm{~mm}$ ) placed in tubular ovens; four, a backpressure regulator (Swagelok, LH2981001). In the case of epimerization reactions, the reactor was loaded with the catalyst $(0.2-0.3 \mathrm{~g}$, sieve fraction $=0.2-0.4 \mathrm{~mm})$ and diluted with quartz $(0.5 \mathrm{~g}$, sieve fraction $=0.2-0.4 \mathrm{~mm})$. After heating at the desired temperature, a liquid feed $\left(0.5 \mathrm{~mL} \mathrm{~min}^{-1}, 0.28 \mathrm{M}\right.$ glucose, arabinose, or xylose aqueous solution) was admitted, and the system was pressurized at 1.0 MPa. For hydrogenations of glucose/ mannose, arabinose/ribose, and xylose/lyxose mixtures, the reactor was loaded with the catalyst $(0.2-0.3 \mathrm{~g}$, sieve fraction $=0.2$ $0.4 \mathrm{~mm}$, diluted with $0.5 \mathrm{~g}$ quartz of the same sieve fraction). The combination of the epimerization and hydrogenation steps was 
studied by using a mixed catalyst bed or two separate catalytic beds operated at different temperatures. In the former case, the reactor was loaded with a mixture of the two catalysts $(0.2 \mathrm{~g} \mathrm{Ru} / \mathrm{C}$, $0.2 \mathrm{~g} \mathrm{Cs-HPA} / \mathrm{C}$, diluted with $0.4 \mathrm{~g}$ quartz). In the latter case, the two reactors were loaded with Cs-HPA/C $(0.4 \mathrm{~g}$, diluted with $0.4 \mathrm{~g}$ quartz) and $\mathrm{Ru} / \mathrm{C}(0.2 \mathrm{~g}$, diluted with $0.6 \mathrm{~g}$ quartz), respectively. Alternatively, the second reactor was filled by using a mixture of the two catalysts $(0.2 \mathrm{~g} \mathrm{Ru} / \mathrm{C}, 0.2 \mathrm{~g} \mathrm{Cs}-\mathrm{HPA} / \mathrm{C}$, diluted with $0.4 \mathrm{~g}$ quartz). The hydrogenation and combined epimerizationhydrogenation reactions were started by following the same proto$\mathrm{col}$ as that for the epimerization reaction but adding a gas feed of $50 \mathrm{~mL}_{\mathrm{H}_{2}} \mathrm{~min}^{-1}$. In all tests, liquid samples were periodically collected at the outlet of the reactor.

Reaction products were isolated by high-performance liquid chromatography (HPLC) in an Agilent 1260 system equipped with a Biorad Aminex HPX-87C column heated at $338 \mathrm{~K}$ and a refractive index detector set at $303 \mathrm{~K}$ by using water $\left(0.450 \mathrm{~mL} \mathrm{~min}^{-1}\right)$ as the eluent. Quantification was attained on the basis of the absolute peak areas. Calibration curves were measured in the $0.05-0.3 \mathrm{M}$ range for the sugars and the corresponding sugar alcohols sorbitol (Sigma-Aldrich, >98\%), mannitol (Fluka, 99\%), arabitol (Acros Organics, 99\%), xylitol (ABCR, 99\%), and ribitol (Sigma-Aldrich, $>99 \%)$. The conversion of substrate $i\left(X_{i}\right)$ and selectivity to the product $k\left(S_{k}\right)$ were calculated as follows [Eqs. (6) and (7)]:

$X_{i}=1-\left(\frac{n_{i, 1}}{n_{i, 0}}\right)$

$S_{\mathrm{k}}=\frac{n_{k, 1}}{n_{i, 0}-n_{i, 1}}$

in which $n$ refers to the moles of $i$ or $k$ and $0 / 1$ to the reaction beginning/end. The conversion of the mixtures of sugars was obtained by summing the conversions of the two aldose epimers. The epimerization equilibrium conversions for glucose, ribose, and arabinose were determined as the conversion observed after $16 \mathrm{~h}$ of reaction by using Cs-HPA as the catalyst and were 35.0, 41.2, and $52.7 \%$, respectively, in good agreement with the literature data. ${ }^{[35]}$

\section{Computational details}

DFT was employed to study the ruthenium-catalyzed reduction of glucose and mannose by using the Vienna Ab Initio Simulation Package (VASP). ${ }^{[36]}$ The exchange and correlation energies were obtained by using the PBE functional. ${ }^{[37]}$ As glucose, mannose, and other intermediates as well as their hydrogenation products sorbitol and mannitol are large molecules, van der Waals correction was performed by using the Grimme's DFT-D2 method ${ }^{[38]}$ with the C6 parameters developed in our group. ${ }^{[39]}$ The inner electrons were represented by projector augmented wave (PAW) pseudopotentials ${ }^{[40]}$ with cutoff energies of $450 \mathrm{eV}$. The calculated lattice parameter for Ru was $2.712 \AA$ ( $c / a=1.581)$, which agrees well with the known experimental value of $2.706 \AA(c / a=1.584) .{ }^{[41]}$ Gas molecules were calculated in a box of $20 \times 20 \times 20 \AA^{3}$. The $\mathrm{Ru} / \mathrm{C}$ catalyst was modeled by a four-layer ruthenium slab with a $p(4 \times 4)$ supercell, for which the two upmost layers were fully relaxed and the remaining atoms at the bottom were fixed to mimic the bulk. A $20 \AA$ thick vacuum region was set between each slab to avoid their interaction. Given that adsorption was performed on one side of the slab, dipole correction was applied to eliminate the spurious contributions arising from the system's asymmetry. Gamma point sampling was used to obtain the adsorption geometries and transition states, and then their energies were calculated with a denser mesh than $30 \AA^{-1}$. The metal atoms were fixed during these processes. An extensive search of potential adsorption conformations was performed by following the adsorption rules previously developed in our group. Solvation contributions for the molecules in the liquid phase were investigated through the multigrid-based (MGCM) methodology. ${ }^{[42]}$ The climbing image nudged elastic band $(\mathrm{Cl}-\mathrm{NEB})^{[43]}$ and improved dimer method (IDM) ${ }^{[44]}$ were employed to locate the transition states in the potential surfaces. All transition states were confirmed with only one imaginary value in the frequency analysis. The most relevant structures were uploaded to the ioChem-BD database. ${ }^{[45]}$

\section{Acknowledgements}

This work was sponsored by the Swiss National Science Foundation (Project Number 200020-159760). Dr. S. Mitchell and E. Vorobjeva are thanked for the microscopic analyses. N.L. and Q.L. are grateful to MINECO (CTQ2015-68770-R) for financial support and to the Barcelona Supercomputing Centre (BSC-RES) for providing the computational resources.

Keywords: epimerization - flow chemistry · heterogeneous catalysis · hydrogenation $\cdot$ sugar alcohols

[1] a) Y.-C. Park, E. J. Oh, J.-H. Jo, Y.-S. Jin, J.-H. Seo, Curr. Opin. Biotechnol. 2016, 37, 105-113; b) P. Mäki-Arvela, B. Holmbom, T. Salmi, D. Y. Murzin, Catal. Rev. 2007, 49, 197-340

[2] A. M. Langkilde, H. Andersson, T. F. Schweizer, P. Würsch, Eur. J. Clin. Nutr. 1994, 48, 768-775.

[3] T. M. S. Wolever, A. Piekarz, M. Holland, K. Younker, Can. J. Diabetes 2002, 26, 356-362.

[4] T. Matsuo, Y. Baba, M. Hashiguchi, K. Takeshita, K. Izumori, H. Suzuki, J. Clin. Biochem. Nutr. 2001, 30, 55-65.

[5] M. Fontana, C. González-Cabezas, Adv. Dent. Res. 2012, 24, 123-128.

[6] F. Zamora, K. Hakkou, A. Alla, J. L. Espartero, S. Muñoz-Guerra, J. A Galbis, J. Polym. Sci. Part A 2005, 43, 6394-6410.

[7] E. L. Kunkes, D. A. Simonetti, R. M. West, J. C. Serrano-Ruiz, C. A. Gärtner, J. A. Dumesic, Science 2008, 322, 417-421.

[8] a) J. C. Serrano-Ruiz, J. A. Dumesic, Energy Environ. Sci. 2011, 4, 83-89; b) M. Rose, R. Palkovits, ChemSusChem 2012, 5, 167-176.

[9] T. Werpy, G. R. Petersen, Top Value Added Chemicals from Biomass: Vol. I-Results of Screening for Potential Candidates from Sugars and Synthesis Gas, DOE/GO-102004-1992,Department of Energy, Washington, DC, 2004.

[10] O. Akinterinwa, R. Khankal, P. C. Cirino, Curr. Opin. Biotechnol. 2008, 19, $461-467$.

[11] a) C. Luo, S. Wang, H. Liu, Angew. Chem. Int. Ed. 2007, 46, 7636-7639; Angew. Chem. 2007, 119, 7780-7783; b) J. V. Karabinos, A. T. Ballun, J. Am. Chem. Soc. 1953, 75, $4501-4502$.

[12] M. Morales, P. Y. Dapsens, I. Giovinazzo, J. Witte, C. Mondelli, S. Papadokonstantakis, K. Hungerbühler, J. Pérez-Ramírez, Energy Environ. Sci. 2015, 8, 558-567.

[13] A. K. Sirkar, US Pat. 4380678, 1983

[14] T. Ona, T. Sonoda, K. Itoh, M. Shibata, Holzforschung 1997, 51, 396-404.

[15] J. Wisnlak, R. Simon, Ind. Eng. Chem. Prod. Res. Dev. 1979, 18, 50-57.

[16] a) R. A. Hales, US Pat. 3484492, 1969; b) H. J. Bart, R. C. Messenböck, C. H. Byers, A. Prior, J. Wolfgang, Chem. Eng. Process. 1996, 35, 459-471.

[17] A. W. Heinen, J. A. Peters, H. van Bekkum, Carbohydr. Res. 2000, 328, 449-457.

[18] M. A. Veksler, Y. I. Petrov, N. G. Geling, E. I. Klabunovskii, Bull. Acad. Sci. USSR Div. Chem. Sci. (Engl. Transl.) 1974, 23, 45-49.

[19] W. M. Kruse, US Pat. 4029878, 1977.

[20] R. Bermejo-Deval, R. Gounder, M. E. Davis, ACS Catal. 2012, 2, $2705-$ 2713. 
[21] A. Takagaki, S. Furusato, R. Kikuchi, S. T. Oyama, ChemSusChem 2015, 8, $3769-3772$.

[22] F. Ju, D. Van der Velde, E. Nikolla, ACS Catal. 2014, 4, 1358-1364.

[23] M. A. Schwegler, P. Vinke, M. van der Eijk, H. van Bekkum, Appl. Catal. A 1992, 80, $41-57$.

[24] R. Sheikh, M.-S. Choi, J.-S. Im, Y.-H. Park, J. Ind. Eng. Chem. 2013, 19, $1413-1419$.

[25] T. Baba, Y. Ono, Appl. Catal. 1986, 22, $321-324$.

[26] a) J. A. R. van Veen, O. Sudmeijer, C. A. Emeis, H. de Wit, J. Chem. Soc. Dalton Trans. 1986, 1825-1831; b) Z. Zhu, R. Tain, C. Rhodes, Can. J. Chem. 2003, 81, 1044-1050.

[27] M. Langpape, J. M. M. Millet, U. S. Ozkan, M. Boudeulle, J. Catal. 1999, $181,80-90$.

[28] V. Bílik, L. Petruš, V. Farkaš, Chem. Zvesti 1975, 29, 690-693.

[29] a) Z. Yan, L. Lin, S. Liu, Energy Fuels 2009, 23, 3853-3858; b) M. Besson, P. Gallezot, Catal. Today 2003, 81, 547-559.

[30] Y. Zhu, J. Zajicek, A. S. Serianni, J. Org. Chem. 2001, 66, 6244-6251.

[31] C. O. da Silva, B. Mennucci, T. Vreven, J. Org. Chem. 2004, 69, 8161 8164.

[32] R. García-Muelas, N. López, J. Phys. Chem. C 2014, 118, 17531-17537.

[33] W. Plazinski, A. Plazinska, M. Drach, Phys. Chem. Chem. Phys. 2015, 17, $21622-21629$.

[34] I. Chorkendorff, J.W. Niemantsverdriet, Concepts of Modern Catalysis and Kinetics, Wiley-VCH, Weinheim, 2006.

[35] S. J. Angyal, Angew. Chem. Int. Ed. Engl. 1969, 8, 157-166; Angew. Chem. 1969, 81, 172-182.
[36] a) G. Kresse, J. Furthmüller, Comput. Mater. Sci. 1996, 6, 15-50; b) G. Kresse, J. Furthmüller, J. Phys. Rev. B 1996, 54, 11169-11186.

[37] J. P. Perdew, K. Burke, M. Ernzerhof, Phys. Rev. Lett. 1996, 77, 3865 3868.

[38] a) S. Grimme, J. Comput. Chem. 2006, 27, 1787-1799; b) T. Bučko, J. Hafner, S. Lebegue, J. G. Angyán, J. Phys. Chem. A 2010, 114, 1181411824.

[39] N. Almora-Barrios, G. Carchini, P. Błoński, N. López, J. Chem. Theory Comput. 2014, 10, 5002-5009.

[40] a) P. E. Blöchl, Phys. Rev. B 1994, 50, 17953-17979; b) G. Kresse, D. Joubert, Phys. Rev. B 1999, 59, 1758-1775.

[41] D. Lide, CRC Handbook of Chemistry and Physics, 84th ed., CRC, Boca Raton, FL, 2003-2004, pp. 12(19-21).

[42] M. Garcia-Ratés, N. López, J. Chem. Theory Comput. 2016, 12, 1331 1341.

[43] a) G. Henkelman, H. Jónsson, J. Chem. Phys. 2000, 113, 9978-9985; b) G. Henkelman, B. P. Uberuaga, H. Jónsson, J. Chem. Phys. 2000, 113, 9901 9904.

[44] A. Heyden, A. T. Bell, F. J. Keil, J. Chem. Phys. 2005, 123, 224101-224114.

[45] M. Álvarez-Moreno, C. de Graaf, N. López, F. Maseras, J. M. Poblet, C. Bo, J. Chem. Inf. Model. 2015, 55, 95-103. 